\title{
Preleção inaugural do curso de direito internacional público em 1959
}

\author{
Braz de Sousa Arruda \\ Catedrático de Direito Internacional Público \\ da Universidade de São Paulo.
}

Le caractère d'ordre juridique est inhérent au droit international, ce caractère étant engendré par la structure de ses normes, qui dans leur ensemble décèlent la forme Iogique du droit, ainsi que par le degré d'accomplissement effectif que le droit international parvient de toute façon à atteindre.

Un ordre juridique est, par définition même, un système d'organisation effective de la vie sociale. Or, c'est justement en envisageant les facteurs de l'accomplissement effectif $\mathrm{du}$ droit international que l'on doit reconnaitre une importance de premier plan à la force morale de cet ordre.

Rappelons les mots fameux de Byndershoek:

"Pacta privatorum tuetur jus civile, pacta principum bona fides" 1

(G. Sperduti - L'individu et le droit international. Recueil des Cours t. 90, p. 736).

Iniciamos hoje o estudo do Direito das Gentes, "Nobilissima Pars Jurisprudentiae".

(1) Questionum Juris Publici Libri II, ed. 1737, Classics of International Law, Oxford, 1930. Lib. II, cap. IX, p. 251. 
Como conceito puro, o Direito é uno e indivisível. ${ }^{2}$

As repartições das matérias é questão de comodidade. $^{3}$

Daí a dificuldade doutrinária de se qualificar o $\mathrm{Di}$ reito das Gentes: Direito Privado superior, ${ }^{4}$ ou como Direito de coordenação, que seria mais privado do que o Direito Privado, segundo BurkhardT.

Conhecem todos a nossa orientação e como encaramos as Humanae res.

$\mathrm{Na}$ realidade, cada vez mais, o Direito Internacional se transforma de um Direito Inter-Estatal em um Direito Humano: Homines quidem pereunt; ipsa Humanitas permanet.

Dizia Saleilles, no seu trabalho - De la personalité juridique, p. 45: "on veut d'abord le resultat on trouve le principe après".

$\mathrm{Na}$ frase de Saleilles existe muito de verdade...

Vamos estudar matéria belíssima: "Le droit interna" tional n'est point emprisonné dans une gangue de textes, sanglé dans un corset de définitions, figé dans un moule, cliché dans le plomb; c'est un droit indompté. frémissant d'idéal, palpitant d'expérience vécue" 6

Legrange, na sua interessantíssima Histoire de Saint Paule, ch. xIII, Paris 1867, p. 334, afirma que a grande beleza da Bíblia está no seu conjunto: "La grande beauté de la Bible est dans son ensemble".

O mesmo podemos dizer do estudo de Direito Internacional Público.

(2) Cf. Tourtoulon, Les principes philosophiques de l'histoire du. Droit, Lausanne, Paris, 1908-1919, p. 526 e sgs.

(3) Benvenuto Donati, L'unitá del diritto e l'unitá della scienza del diritto a proposito della distinzione del diritto in pubblico e privato. Rev. Intern. da teoria do D. t. I, p. 120 e sgs.

(4) a Higher private Law. Lauterpacht, analogies, p. 81.

(5) SENECA.

(6) RenaRd, Le droit, la logique et le bon sens, Paris 1925, p. 293. 
O Direito deve ser estudado escoimado de todo elemento extra-jurídico.

Pode no entanto ser submetido a uma apreciação moral. Querer muitas vêzes moralizar o Direito é tornar a moral imoral, como já salientava QuAdri, no seu Direito Internacional, segunda parte, p. 35. A ciência do Direito deve abster-se de indagar se o Direito positivo é justo ou injusto: a questão é de moral.

\section{II}

\section{Direito Internacional Positivo}

A fonte suprema da ordem internacional é o costume. .Este é uma regra positiva pois vive no mundo positivo dos fatos.

Ja antes de Kelsen, Vanni na sua Filosofia do Direito -dissera que o caráter jurídico de uma norma se baseia na ordem juridica preexistente, sendo cada regra o ủltimo anel de uma cadeia.

Kelsen afirma hoje: os Estados são obrigados a pro:ceder como agiram costumeiramente. ${ }^{7}$

Paralelamente à escola austríaca, desenvolve-se na Itália a escola dogmática de Perassi.

A regra jurídica positiva se origina de um ato de .. criação realizado na história, tornando-se perceptivel do exterior. ${ }^{8}$

"Alles Recht ist positiv, alles Recht ist "Gesetzt" und nur positives Recht ist Recht". 9

Erram os que pensam que a prática de um ato ilícito internacional significa falência do Direito das Gentes.

(7) V. GugGenheim I, p. 9.

(8) BERGBOHм - Jurisprudenz und Rechtsphilosophie, I ed. Leipzig, 1892 , p. 546.

(9) id. p. 52. 
Notemos que o ato ilícito não é uma violação e nem uma negação do Direito, mas um comportamento humano definido pelo Direito como a condição de uma sanção determinada pelo próprio Direito.

A sanção é uma reação coercitiva do grupo social contra a violação de um dever garantido pelo Direito positivo. Existe uma coação psicológica -- Coactio dormiens.

A sanção é um mal com que a autoridade pode nos ameaçar.

\section{III}

Vejamos qual seja o objeto e quais as características ،do Direito das Gentes.

O objeto do nosso curso é um estudo das regras do Direito que regem a organização e as relações da sociedade internacional. $\mathrm{Na}$ realidade estas regras constituem -o que se chama Direito Internacional Público ou Direito das Gentes.

Quem primeiro usou da expressão Direito Internacio'nal, international Law, em 1780, foi Bentham, na tradução do trabalho de Zouch, intitulado: "Juris et judicii fecialis sive de jure inter gentes et quaestionum de eodem explicatio".

Hoje o Direito Internacional tem por objeto: 1) o conjunto das regras relativas à Constituição e funcionamento das organizações internacionais criadas pelos Estados, como a Organização das Nações Unidas; 2) o conjunto de regras que se impõem aos Estados nas suas relações recíprocas.

Estas regras são juridicamente obrigatórias, constituem um fato da vida internacional.

Existe na ONU uma comissão jurídica que examina na ordem do dia da Assembléia as questões que têm um aspeto jurídico, referindo-se aos direitos e obrigações dos Estados-Membros ou da própria Organização Internacional. 
O Direito das Gentes é aplicado pelos Tribunais Internacionais e é invocado pelos Estados nas reclamações diplomáticas.

Como veremos, o Direito Internacional é obrigatório para os Estados e tem preeminência sôbre o Direito Interno.

\section{IV}

\section{Características do Direito Internacional}

O Direito Interno, em regra, obriga nos quadros territoriais do Estado, onde existe Autoridade Suprema à qual são subordinados os indivíduos. Assim: 1) o Direito elaborado pelo legislador se impõe a todos; 2) o respeito ao Direito é assegurado pelos Tribunais com suas decisões obrigatórias, aplicando e interpretando o Direito; 3) a sanção do Direito é assegurada pela autoridade pública sob várias formas de coação; 4) o uso da fôrça material é monopólio do poder público.

O Direito Interno é um Direito sôbre os indivíduos.

No Direito Internacional, que se aplica às relações entre Estados e sendo êstes soberanos, não existe uma autoridade superior, e o Direito das Gentes é um Direito de coordenação e não de subordinação.

Daí resulta:

1) a elaboração do Direito se faz pela ação dos que a êle são subordinados, os Estados. Não existe uma autoridade legislativa superior aos Estados.

2) a intervenção do juiz supõe um acôrdo entre os Estados interessados.

3) a sanção do Direito é imperfeita, não existe em regra sanção penal, a sanção é principalmente assegurada pelos próprios Estados.

4) as grandes potências têm mais possibilidades de assegurar o respeito do Direito e daí exercerem uma liderança de fato da sociedade internacional. 
A influência dos elementos políticos torna a armadura lécnica de Direito Internacional mais fraca e elementos extra-jurídicos tornam muitas vêzes a sua aplicação precária.

Esta situação explica a tendência de certos mestres afirmando que o chamado Direito Internacional nada mais é do que um conglomerado de regras morais.

Esta concepção é falsa, porque as Organizações Internacionais, como os Estados, se consideram juridicamente obrigados.

\section{V \\ Direito Internacional e relaçôes internacionais}

Na América do Norte existe uma tendência para considerar certas questões jurídicas como relações internacionais ou organização internacional.

Entre nós, o estudo do Direito Internacional compreende as regras e as instituições ligadas à vida internacional, englobando o que os americanos denominam "relações internacionais"

O conjunto da vida internacional exerce influência no desenvolvimento e no conteúdo do Direito Internacional.

A politica internacional atua poderosamente no Direito das Gentes.

O Direito Internacional costumeiro, não escrito, resulta do comportamento dos Estados que se consideram obrigados a agir de uma certa maneira.

Em uma civilização técnica o Direito Internacional se harmoniza com as necessidades da vida internacional decorrentes de progressos técnicos: aviação, rádio-difusão, etc.

Assim as transformações das condições de vida internacional explicam e condicionam as transformações do Direito. 


\title{
VI
}

\section{Conceito do Direito Internacíonal"}

\author{
OPPENHEIM, I $\S 1$. \\ BRIERLY, RCA v. 23 (1928), p. $467-549$; v. 59 (1936),- \\ p. 5-34. \\ Scelle: Précis (1932) I, 27. Manuel (1934), 19: \\ Spiropoulos: Théorie générale du D. I., 8. \\ Aguilar: D. I. Público (1952), I, cap. 1. \\ ROUSSEAU: p. 1-105.
}

Divergem os autores na conceituação da nossa disciplina, Direito Internacional, Direito das Gentes (droit des gens, law of nations, diritto delle genti, Völkerrecht), Direito das Nações ou, como queria Kant, Direito dos Estados.

Esta variedade se explica fàcilmente porque o investigador tem liberdade plena para delimitar e denominar o objeto de seu estudo.

No entanto, deixando de parte puras abstrações, devemos levar em conta as ordenações jurídicas concretas.

Muitos internacionalistas se preocupam exclusivamente com a procura de um Direito teórico ou racional.

Tradicional é a expressão "Direito Natural", desde Vitória, Suarez e Grócio.

Pouco importa que, modernamente, a expressão "Direito Natural" seja empregada com significação muito diferente da usada por Grócio.

No Recueil des Cours de Haya, t. 54, Le Fur refere-se às expressões "Direito objetivo ou racional, natural ou! intuitivo, científico, ideal, livre" etc.

Em suma, o Direito Internacional seria um conjunto de regras destinadas a assegurar a ordem de acôrdo com a justiça.

Evidentemente o Direito, como veremos, tem um fundamento meta-jurídico. Mas o que interessa principalmente neste curso é o Direito Internacional positivo. 
O Direito é um conjunto de regras destinadas a assegurar a ordem na sociedade, limitando a ação dos homens e protegendo os seus interêsses legítimos.

o Direito positivo é o que é revestido de uma fôrça de aplicação.

Todo tratado de Direito das Gentes teórico é um sistema de política internacional, como salienta Funck-Brentano e Sorel. ${ }^{10}$

O grande Vattel, um dos clássicos do Direito Internacional, já afirmava que cada nação é que julga o que a consciência exige dela. ${ }^{11}$

Assim os governos não se baseiam nas opiniões dos: maiores internacionalistas, mas sim naquilo que é considerado realmente como obrigatório nas relações internacionais.

As regras reconhecidas como legalmente obrigatórias, emanam não sòmente do reconhecimento dos Estados mas também de outros órgãos e mesmo da doutrina, desde que ela anuncie uma regra preexistente.

O que interessa precipuamente é a fôrça de aplicação" da regra jurídica.

\section{VII}

O Direito Internacional é aquêle que regula as relações na comunhão internacional.

Evidentemente, o Direito das Gentes implica na existência de uma sociedade internacional.

Esta é um conjunto de indivíduos ligados por interêsses comuns, materiais e espirituais.

Como veremos, o Direito Internacional regula principalmente relações entre Estados e não relações de individuos.

(10) Funck-Bretano e Sorel - Précis du droit de gens, Pariś, 1877 , p. 2.

(11) Vattel - Le droit de gens, Préliminaires, § 16 e $\S 21$. 
É uma característica do Direito das Gentes, Nada impede contudo uma transformação na estrutura da comunidade internacional.

Quando estudarmos os sujeitos do Direito Internacional, verificaremos que os indivíduos também podem ter direitos na órbita internacional.

O dogma de que os únicos sujeitos do Direito Internacional são os Estados é teòricamente falso e contrário ao Direito positivo. ${ }^{12}$

\section{VIII}

O Direito Internacional é o que rege a comunidade internacional.Esta, no curso da história, adquiriu a unidade sociológica e normativa.

Dentro desta comunidade maior existem outras. Algumas com fins análogos aos do Estado (associações organizadas pelos Estados, insurgentes), outras, só parcialmente são reguladas pelo Direito Internacional (Igreja Católica).

Hoje o Direito Internacional compreende não só normas cujo objeto é a relação entre Estados e outras comunidades, reconhecidas como sujeitos dêle, mas também regula, muitas vêzes, diretamente a conduta dos indivíduos.

A comunidade internacional vai se convertendo paulatinamente em comunidade humana.

No Direito Internacional clássico as sançôes eram coletivas, contra comunidades humanas (represálias, guerras).

Atualmente, além das sanções coletivas, existerm as individuais, Estas normas têm a mesma estrutura do Direito interno, mas foram criadas por um procedimento internacional.

(12) Kelsen, RCA, t. 42, p. 146. 


\section{IX}

Podemos dizer que, de uma certa forma, existiram no rurso da história várias modalidades de Direito Internacional.

Quando afirmamos que o Direito Internacional é relalivamente recente, um produto de condições peculiares ao continente Europeu na segunda metade da Idade Média, referimo-nos ao Direito Internacional como é concebido modernamente.

Realmente outras modalidades de Direito Internacional existiram na antiguidade: Direito. Internacional grego, mediterrâneo: ${ }^{13}$ Direito Internacional índico; ${ }^{14} \mathrm{Di}$ reito Internacional chinês. ${ }^{15}$

Ainda poderíamos fazer referência ao Direito Internacional oriental europeu ${ }^{16} \mathrm{e}$ ao islâmico. ${ }^{17}$

\section{$\mathrm{X}$}

\section{Definição de Oppenheim}

O grande mestre OPPENHEIM no seu clássico tratado do Direito Internacional, $\S 1$, conceitua o Direito das Gentes dizendo que: "Law of Nations or International Law (Droit des gens, Volkerrecht) is the name for the body of customary and conventional rules which are considered legally binding by civilised States in their intercourse with each other".

(13) Phillipson $\rightarrow$ The international law and custon of ancient Greece and Rome (1911). KORFF - I (1923).

(14) VisWaNATHA - International law in ancient India (1925).

(15) Siu-Tschoan-Pao - Le droit des gens et la Chine antique (1926).

(16) TAUBE, RCA 11, (1926-I), 345 e 67 (1938-I), 237.

(17) RECHID - l'Islam et le droit des gens, RCA, 60 (1937-II), VISMARA, Bisancio e l'Islam (1950).

$13-2^{\circ}-$ F. D. 
O Direito Internacional seria o corpo de normas costumeiras e convencionais, consideradas legalmente obrigatórias pelos Estados civilizados, em suas relações recíprocas.

Verificaremos, mais tarde, que os Estados não são os únicos sujeitos do Direito das Gentes.

HaLL diz: "International Law consists in certain rules of conduct which modern civilised states regard as being binding on them in their relations with one another with a force comparable in nature and degree to that binding conscientious person to obey the laws of his country, and with they also regard as being enforceable by appropriate means in case of infringement. ${ }^{18}$

Achamos razoável a noção seguinte: "Direito Internacional Público é o corpo de costumes, regras e princípios, reconhecidos como legalmente obrigatórios pelos Estados e outras pessoas internacionais em suas relações reciprocas".

Examinaremos também o fundamento da doutrina consensualista mostrando que, acima da vontade dos Estados, está o princípio metajurídico explicativo da obrigatoriedade das normas jurídicas internacionais.

\section{XI}

O Direito Internacional é um conjunto de normas juridicas obrigatórias na comunidade internacional. A norma de Direito Internacional é, em princípio, a que é aplicada, na convicção de que é legalmente obrigatória, pelos tribunais internacionais ou pelos órgãos dos sujeitos de Direito das Gentes.

O princípio fundamental do Direito das Gentes é o princípio da bôa fé. ${ }^{19}$

(18) International Law (1927), p. 1.

(19) HaLL - § 13. 
Baseanđo-se nas exposições de Cícero e de outros legistas romanos e medievais (BALdo, Alciato), Gentilis ${ }^{20}$ reconheceu o princípio da bôa fé como qualidade necessária do Direito das Gentes (principalmente Direito da guerra e interpretação de acordos), ao passo que depois Grócio ${ }^{21}$ rejeitou para o Direito das Gentes a distinção romana de atos stricti juris e bonae fidei.

O principio da bôa fé tem consequências de primordial importância no Direito das Gentes, tanto na parte das normas sôbre os acordos internacionais (principalmente pacta servanda sunt) com tôdas suas consequências para a questão de forma e interpretação de acordos internacionais, como em outras partes, por exemplo, o principio da proporçâao no Direito Diplomático e Consular, bem como no Direito da guerra.

"Pacta privatorum tuetur jus civile, pacta Principum bona fides. Hanci tollio, - tollis mutua inter Principes commercia... Quin et tollis ipsum jus gentium. ${ }^{22}$

Hoje, os meios coativos ${ }^{23}$ não têm sanções e assim o Direito Internacional moderno está vinculado a normas morais.

A bôa fé é a base do edifício do Direito Internacional, não observada, êle cai por terra.

E o fundamento dos tratados internacionais, informa sua interpretação e limita os direitos conferidos pela ordenação jurídica internacional, porque o exercício dêstes direitos de forma incompatível com o princípio de bôa fé constitui abuso de Direito.

A bôa fé é a base das sanções internacionais. ${ }^{24}$

(20) Gentilis - livro II, parte IV.

(21) GRócio - Livro II, parte XVI, § 11.

(22) BYNKERSCHOEK - Quaestionium iuris publici, librì duo (1737), cap. II.

(23) Carta da onU - art. 39.

(24) V. Papaligouras - Théorie de la Societé Internationale. 


\section{XII \\ Direito Internacional e moral internacional}

O Direito Internacional é fruto da moral cristã. O Direito, que hoje denominamos Direito Internacional, desenvolveu-se entre os Estados cristãos da Europa, na segunda metade da Idade Média e é resultado de sua cultura.

O Direito Internacional, tanto quanto os outros ramos do Direito, sofre a influência dos pontos de vista de cada 'época. Nos séculos xix e $\mathrm{xx}$, os países se submeteram a extensas limitações de soberania para possibilitar uma melhor convivência internacional. Quanto mais progride a moral política e se esclarece a opinião pública, mais também se protegem os interêsses humanos.

\section{XIII}

\section{Direito Internacional e direito interno}

Não devemos aplicar ao Direito Internacional, sem muita cautela, princípios do Direito Privado. As normas do Direito das Gentes são fundamentalmente diversas das de outros ramos do Direito.

O Professor francês Renard formulou com acêrto a diferença entre o caráter geral e os métodos do Direito das Gentes, Direito Público e Direito Privado.

$O$ Direito considera as relações reais e, ao mesmo tempo, visa a consecução, ao menos a aproximação, de um ideal moral e político. O Direito procura, pois, harmonizar a realidade com a concepção, isto é, o concreto com o abstrato, a vida com a norma. Na esfera do Direito, portanto, estão as diferenças quanto ao grau em que as normas podem ser abstratas. O principio do Direito Privado costuma ser mais abstrato; o Direito Público tem que consideràr mais as relações reais, ou interêsse de determi- 
nado país, tem que ser menos sujeito ao espírito do abstrato.

O Direito Internacional, mais de que qualquer outro ramo do Direito, tem que tomar em consideração, em cada caso, as relações reais, pois a aplicação inconsiderada de normas abstratas poderia causar a destruição do sistema das relações internacionais.

\section{XIV}

\section{Direito Internacional e Direito Romano}

Vejamos agora a influência do Direito Romano. Em virtude da influência que o Direito Romano exerceu, tanto no desenvolvimento do Direito na Idade Média como em épocas posteriores, principalmente na Itália, Holanda, França, Alemanha e países Ibéricos, os escritos dos autores sôbre Direito das Gentes refletem grandemente a influência do sistema e concepções do Direito Romano e, frequentemente, a prática aplica essas concepções. Os fundadores do Direito Internacional, com Gentulis, Vitoria e GRócro à frente, estavam principalmente imbuídos dos princípios do Direito Romano, e Gentilis muitas vêzes se funda exclusivamente nos romanistas.

Entretanto, Grócio já refutava a concepção de que as normas do Direito Romano tinham aplicação "o quanto possível" nos problemas de Direito das Gentes.

Embora, portanto, històricamente a influência de Direito Privado Romano e seu ensino no Direito das Gentes tenha sido grande (questões de conquista e perda do território) e nos chamados princípios gerais do Direito, aceitos pelos países civilizados, esta influência, que perdura até hoje, não significa que se possa aplicar no Direito Internacional contemporâneo o Direito Romano, baseando-se sòmente na analogia sem se justificar que suas normas foram aceitas como normas jurídicas internacionais, obrigatórias na sociedade internacional. 


\section{XV}

\section{Fundamento do Direito Internacional}

Como veremos, o fundamento da validade do Direito está fora do campo jurídico. "O Direito Internacional", como diz um eminente escritor inglês ${ }^{25}$, "é hoje mais respeitado e obedecido pelos Estados do que, há seis séculos, a lei inglêsa por um poderoso senhor feudal".

0 que é verdade é que, em regra, o Direito das Gentes é respeitado e, quando violado, a sua violação é sempre fatal à quem a pratica.

(25) FIGGIS, From Gerson to Grotius, p. 16. 